\title{
HTX-019 via 2-min injection or 30-min infusion in healthy subjects
}

Thomas Ottoboni*,1, Michael Lauw ${ }^{1}$, Mary Rose Keller ${ }^{1}$, Matt Cravets ${ }^{1}$, Kimberly Manhard ${ }^{1}$, Neil Clendeninn ${ }^{1} \&$ Barry Quart ${ }^{1}$

${ }^{1}$ Heron Therapeutics, Inc., 4242 Campus Point Court, Suite 200, San Diego, CA 92121, USA

*Author for correspondence: Tel.: +1 650261 3003; Fax: +1 650365 6490; TOttoboni@herontx.com

\begin{abstract}
Aim: HTX-019 (CINVANTI ${ }^{\circledR}$ [aprepitant injectable emulsion]) is a neurokinin 1 receptor antagonist approved for preventing acute and delayed chemotherapy-induced nausea and vomiting (CINV). HTX-019 is free of polysorbate 80 and other synthetic surfactants and showed bioequivalence to and a more favorable safety profile than fosaprepitant when administered as a 30-min infusion in healthy subjects. The shortage of small-volume parenteral solutions led to a recommendation to administer HTX-019 by intravenous push. The objectives were to evaluate pharmacokinetics, tolerability and safety following HTX-019 administration by injection versus infusion. Materials \& methods: Study comprised Part A, a pilot Phase I, single-center, randomized, pharmacokinetic, safety and tolerability, open-label study, followed by Part B, a two-sequence crossover study of HTX-019 $130 \mathrm{mg}$ in healthy adults, via injection and infusion. Blood samples were evaluated for aprepitant pharmacokinetics and bioequivalence. Safety evaluations included treatment-emergent adverse events (TEAEs), vital signs, clinical laboratory testing and electrocardiograms. Results: In Part A, 24 subjects were randomly assigned to three cohorts ( $\mathrm{n}=8$ per cohort) and received HTX-019 $130 \mathrm{mg}$, administered intravenously over $15 \mathrm{~min}$ (cohort 1), 5 min (cohort 2) or $2 \mathrm{~min}$ (cohort 3). Progression to Part B occurred after acceptable tolerability was established in cohorts 2 and 3. In Part B, 50 randomized subjects received a 2-min injection (9 ml/min) and 30-min infusion (296 ml/h) of HTX-019 130 mg. Bioequivalence was demonstrated for HTX-019 injection and infusion. Both administration methods via a peripheral line were well tolerated; eight subjects experienced 11 TEAEs (six related) following injection and nine experienced 14 TEAEs (nine related) following infusion. Headache and fatigue were the most prevalent treatment-related TEAEs; one subject per group experienced feeling hot $\leq 30$ min after drug administration. Conclusion: Pharmacokinetic and tolerability profiles of 2-min HTX-019 injection support this potential alternative administration method for CINV prevention.
\end{abstract}

Lay abstract: This study assesses the management of a common side effect of chemotherapy, known as chemotherapy-induced nausea and vomiting (CINV), and addresses a major shortage of small-volume solutions and intravenous bags used to deliver treatment to prevent CINV. Although effective treatments to prevent CINV are available, a high percentage of patients with cancer receiving chemotherapy still experience this side effect. HTX-019, an injectable emulsion of aprepitant, was approved in 2017 as a 30-min infusion to prevent CINV associated with chemotherapy. In November 2017, US FDA announced a shortage of small-volume parenteral solutions, including those used in administering HTX-019. The American Society of Health-System Pharmacists recommended switching the delivery of treatments by infusion to iv. push (injection over 5 min or less) whenever possible. In this study, HTX-019 $130 \mathrm{mg}$ given as a 2-min injection was comparable in effectiveness and safety to the 30-min infusion, and both methods of administration were well tolerated. These findings confirm the short injection as an alternative method of administering HTX-019 to prevent CINV, reducing the need for iv. bags. 


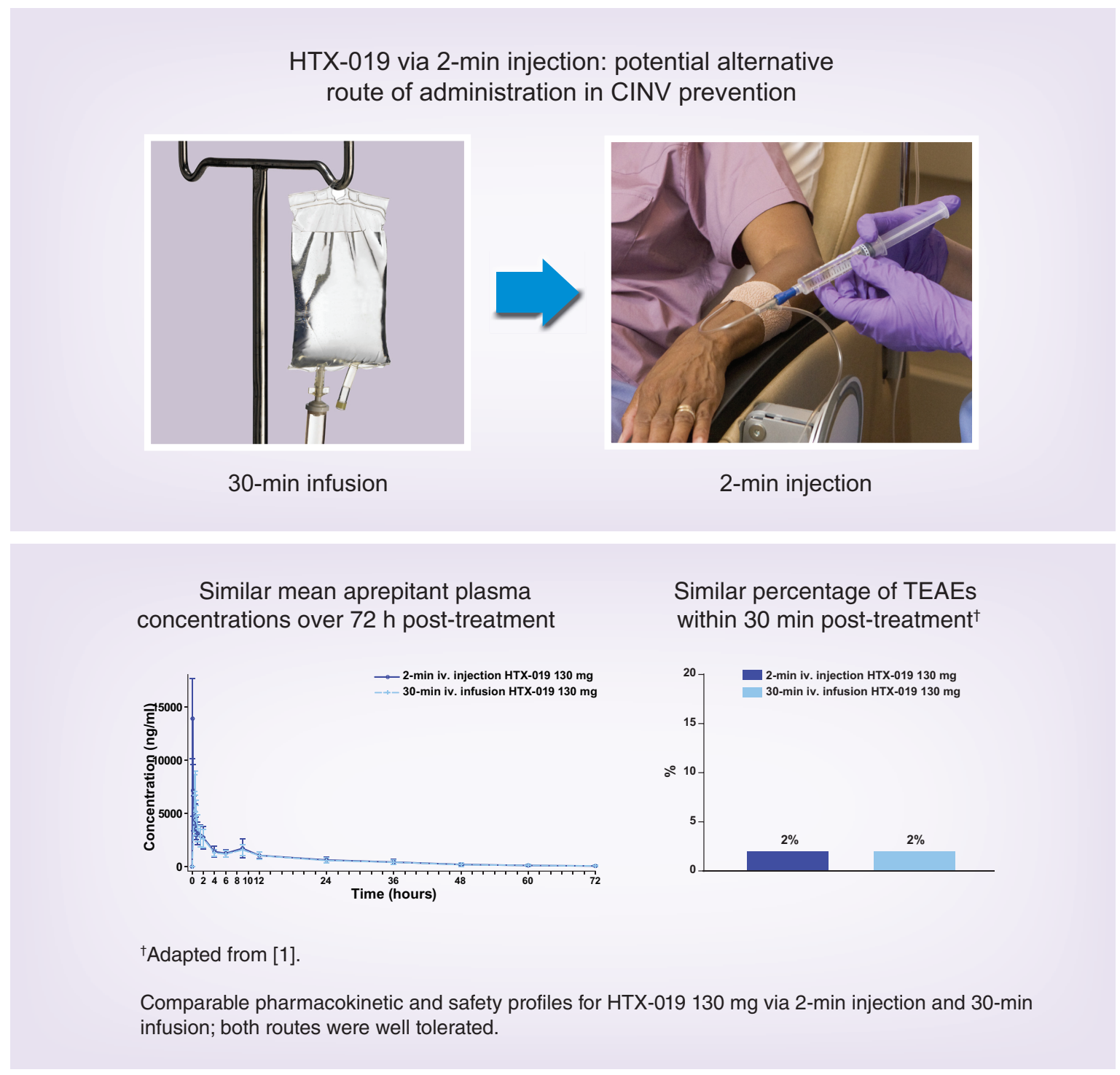

First draft submitted: 19 October 2018; Accepted for publication: 22 November 2018; Published online: 21 December 2018

Keywords: aprepitant • bioequivalence • CINV • fosaprepitant • HTX-019 • short injection

Aprepitant is a substance P neurokinin 1 receptor antagonist (NK-1 RA), used in combination with other antiemetics as part of guideline-recommended regimens for the prevention of acute and delayed chemotherapy-induced nausea and vomiting (CINV) in patients with cancer receiving highly emetogenic (HEC) or moderately emetogenic chemotherapy (MEC) [2-5]. Because of its low water solubility, aprepitant was initially available only as an orally bioavailable product (EMEND capsules). In 2008, an intravenous (iv.) formulation was approved in the USA for CINV prevention in combination with other antiemetics, using the more water-soluble prodrug fosaprepitant (EMEND for injection; Merck \& Co., NJ, USA) [6]; however, even with increased solubility, fosaprepitant still required the surfactant polysorbate 80 , which has been associated with hypersensitivity reactions (HSRs) and infusion-site adverse events (ISAEs) [7,8].

Given the safety issues of fosaprepitant, new NK-1 RAs have been developed: a new aprepitant iv. surfactantfree formulation and a new molecular entity, rolapitant. The new aprepitant injectable emulsion, HTX-019 (CINVANTI ${ }^{\circledR}$; Heron Therapeutics, Inc., CA, USA), was recently approved for the prevention of acute and delayed CINV, in combination with other antiemetics, in adult patients with cancer receiving HEC (130 mg) 
or MEC (100 mg), and is infused over $30 \mathrm{~min}$ [9]. Unlike fosaprepitant, HTX-019 includes compendial lipid excipients with an extensive history of use in parenteral nutrition emulsions and is free of polysorbate 80 and other synthetic surfactants, which have been associated with HSRs and ISAEs [7,8]. The excipients used in the HTX-019 iv. formulation (egg lecithin, ethanol, sodium oleate, soybean oil, sucrose and water) [9] allow aprepitant, which is practically insoluble in water, to be incorporated into an emulsion, negating the need for synthetic surfactants and their associated toxicities.

The current National Comprehensive Cancer Network guidelines list HTX-019 as a category 1 recommendation for HEC and MEC, both using the $130 \mathrm{mg}$ iv. dose [2]. HTX-019 was recently approved as a 30-min infusion by the US FDA [9] for use in adults, in combination with other antiemetics, for the prevention of acute and delayed nausea and vomiting with initial and repeat courses of HEC and MEC. In two earlier bioequivalence studies, HTX-019 displayed a more tolerable safety profile than fosaprepitant, as the proportion of subjects who reported any treatment-emergent adverse events (TEAEs) and the total number of TEAEs were lower with HTX-019 than with fosaprepitant. Also, the percentage of subjects with treatment-related TEAEs and the number of treatmentrelated TEAEs were lower with HTX-019 treatment than with fosaprepitant treatment $[10,11]$.

The current acute shortage of iv. fluids and bags, as well as the desire to reduce administration times, has prompted a need to administer small-volume parenteral solution products as short injections (over 5 min or less) [12]. The present study was designed to evaluate the relative pharmacokinetic (PK) and safety of HTX-019 given as a 2-min iv. push injection versus a 30-min infusion. Reported here are results obtained from the crossover study (Part B), which evaluated PK safety and tolerability in subjects receiving a 2 -min injection versus 30 -min infusion.

\section{Materials \& methods}

\section{Study design \& objectives}

This Phase I, single-center, randomized, open-label clinical study of the tolerability and safety of HTX-019 $130 \mathrm{mg}$ consisted of two parts: Part A was a pilot iv. injection-rate study, and Part B was a crossover study of the injection duration selected in Part A compared with the 30-min infusion. The primary objective of Part A was to evaluate the tolerability and safety of single doses of HTX-019 $130 \mathrm{mg}$ injected over 15, 5 and $2 \mathrm{~min}$; the secondary objective was to assess the PK of plasma aprepitant following single doses of HTX-019 $130 \mathrm{mg}$ given over the same injection times. The primary objective of Part B was to evaluate the PK of plasma aprepitant following a single dose of HTX-019 $130 \mathrm{mg}$ administered iv. as a 2-min injection or as a 30-min infusion; the secondary objective was to assess the safety and tolerability of a single dose of HTX-019 $130 \mathrm{mg}$ administered over the same injection or infusion times.

Healthy men and women aged $18-55$ years with bodyweight $\geq 50 \mathrm{~kg}$ and body mass index $18-35 \mathrm{~kg} / \mathrm{m}^{2}$ were enrolled. Subjects who were pregnant, were breastfeeding, had a history of drug or alcohol dependence within the past year, were currently smoking or had any condition possibly affecting drug absorption were excluded. Subjects may not have had a history or presence at screening of a clinically significant abnormal 12-lead electrocardiogram (ECG): an ECG with QT interval corrected by Fridericia's formula $>470 \mathrm{~ms}$ (women) or $>450 \mathrm{~ms}$ (men), a PR interval $>240 \mathrm{~ms}$ or a QRS complex $>110 \mathrm{~ms}$.

\section{Treatment regimens \& administration}

In Part A (Supplementary Figure 1), 24 subjects were randomly assigned to one of three cohorts. Each cohort received HTX-019 $130 \mathrm{mg}$ iv. injection, administered over $15 \mathrm{~min}$ (cohort $1: \mathrm{n}=8$; injection rate, $1.2 \mathrm{ml} / \mathrm{min}$ ), $5 \mathrm{~min}$ (cohort 2: $\mathrm{n}=8$; rate, $3.6 \mathrm{ml} / \mathrm{min}$ ) or $2 \mathrm{~min}$ (cohort 3: $\mathrm{n}=8$; rate, $9 \mathrm{ml} / \mathrm{min}$ ), with the decision to progress to the next cohort made after all subjects in each cohort completed a 1-h safety observation period. Subjects were confined to the clinic from the morning of day 1 through day 4 , for a total of $\sim 5$ days per cohort. Subjects in Part A were not eligible for Part B, which would proceed only after acceptable tolerability was established in cohorts 2 or 3 of Part A. If both cohorts 2 and 3 were well tolerated, then Part B included the 2-min injection of HTX-019. Only the results from Part B are reported here.

In Part B (Supplementary Figure 2), based on the good tolerability of the 2-min injection, 50 subjects received a 2-min injection (rate, $9 \mathrm{ml} / \mathrm{min}$; treatment A) and a 30-min infusion (rate, $296 \mathrm{ml} / \mathrm{h}, 148 \mathrm{ml}$ tota; treatment B) of HTX-019 $130 \mathrm{mg}$ in a two-treatment, two-period, two-sequence crossover design. Subjects were randomized in a 1:1 ratio to their treatment sequence (25 subjects each, either $A B$ or $B A$ ), administered in two consecutive treatment periods separated by at least 7 days between doses. Different iv. sites were used, since the catheter was 
removed during the washout period. Subjects were confined to the clinic from the morning of day -1 through the end of period 2, for a total of $\sim 12$ days. A follow-up phone call was made 7 days after dosing for all subjects.

\section{Assessments}

Blood samples for aprepitant PK analysis were collected before dosing and at specific time points for Parts A and B, based on the length of the injection and infusion times. For the 2-min injection, blood samples were taken before dosing and at 5, 9, 17, 30 and $45 \mathrm{~min}$. For the 5-min injection, blood samples were taken before dosing and at 8, 12, 20,30 and $45 \mathrm{~min}$. For the 15-min injection, blood samples were taken before dosing and at 15, 19,23,30 and 45 $\mathrm{min}$. For the 30-min infusion, blood samples were taken before dosing and at 28, 30, 34, 38 and $45 \mathrm{~min}$. For all the injection and infusion times, blood samples were also collected at 1, 1.5, 2, 4, 6, 9, 12, 24, 36, 48, 60 and $72 \mathrm{~h}$ after the start of the infusion. The following plasma PK parameters were assessed: area under the plasma concentrationtime curve (AUC) from time zero to time of last measurable plasma concentration $\left(\mathrm{AUC}_{0 \text {-last }}\right)$, $\mathrm{AUC}$ from time zero extrapolated to infinity $\left(\mathrm{AUC}_{0 \text {-inf }}\right)$, maximum observed plasma concentration $\left(\mathrm{C}_{\max }\right)$, plasma concentration at $12 \mathrm{~h}\left(\mathrm{C}_{12 \mathrm{~h}}\right)$, plasma concentration at $24 \mathrm{~h}\left(\mathrm{C}_{24 \mathrm{~h}}\right)$, time at which $\mathrm{C}_{\max }$ occurred $\left(\mathrm{T}_{\max }\right)$, apparent terminal elimination rate constant $(\lambda z)$ and apparent terminal elimination half-life $\left(t_{1 / 2}\right)$. Aprepitant plasma concentrations were determined using a validated liquid chromatography/mass spectrometry method [13].

Safety assessments for Parts A and B included TEAEs (overall, by relation to study treatment, and by severity). Physical examination, 12-lead ECG and clinical laboratory assessments (hematology, serum chemistry and urinalysis) were performed, and vital signs were taken at check-in (day 1), the end of period 1 (day 4) and the end of period 2 (day 11). Treatment-related TEAEs included all those considered by the investigator to be possibly related to the study drug. TEAEs occurring within 30 and $60 \mathrm{~min}$ after the start of dosing are also summarized.

\section{Statistical analysis}

This study was not sized by a statistical power calculation. Continuous variables were assessed using descriptive statistics for each scheduled time point, by study part and by treatment. Analysis to determine bioequivalence was performed through assessment of the PK parameters: $\mathrm{AUC}_{0 \text {-last }}, \mathrm{AUC}_{0 \text {-inf }}$ and $\mathrm{C}_{12 \mathrm{~h}}$. Treatment least squares (LS) mean differences and 90\% confidence intervals (CIs) for the difference (treatment A [test] minus treatment $\mathrm{B}$ [reference]) were constructed for the in-scale values of each parameter, back-transformed and expressed as a percentage geometric mean ratio (GMR). Bioequivalence was determined if the $90 \%$ CI of the GMR was contained within the default equivalence limits of $80-125 \%$.

Mean aprepitant plasma concentration-time profiles were plotted on linear and semilogarithmic scales. Individual concentration-time plots and spaghetti plots were also generated. Pharmacokinetic parameters were calculated with noncompartmental methods for all evaluable subjects using actual or nominal (if actual time was missing) sampling times.

\section{Results}

Subjects

The demographics and baseline characteristics of subjects enrolled in Part A $(N=24)$ are summarized in Supplementary Table 1 and Part B ( $n=50 ; 25$ per treatment sequence) in Table 1. Results from Part A are summarized in the Supplementary materials section, and demonstrate comparable PK and tolerable safety profiles for 15-, 5- and 2-min iv. injections, which allowed for progression to Part B of the study (Supplementary Figure 3; Supplementary Tables $2 \& 3$ ). In Part B, 50 subjects (31 men, 19 women) received a 2-min injection and a 30-min infusion of HTX-019 $130 \mathrm{mg}$ in a two-treatment, two-period, two-sequence crossover design. No sex-based differences in PK, bioequivalence or safety profiles were observed.

\section{Pharmacokinetics \& bioequivalence of HTX-019 injection \& infusion}

As expected, $T_{\max }$ was reached more rapidly and $\mathrm{C}_{\max }$ was higher after an HTX-019 injection compared with infusion; mean aprepitant plasma concentrations were similar for the two methods of administration over $72 \mathrm{~h}$ post-treatment (Figure 1). More specifically, aprepitant peak plasma concentrations occurred at $\sim 5 \mathrm{~min}$ for injection and $30 \mathrm{~min}$ for infusion. For both methods of administration, plasma aprepitant concentrations quickly decreased following $\mathrm{C}_{\max }$ at the 4-h time point, entered the terminal elimination phase at $\sim 12 \mathrm{~h}$ and remained quantifiable $(>10 \mathrm{ng} / \mathrm{ml})$ in most subjects up to $72 \mathrm{~h}$ after the start of administration. 
Table 1. Demographics and baseline characteristics (Part B).

Parameters

Sequence 1

Age, mean (SD), years

Weight, mean (SD), kg

Height, mean (SD), cm

Body mass index, mean (SD), $\mathrm{kg} / \mathrm{m}^{2}$

Sex, $\mathrm{n}(\%)$ :

- Female

- Male

Race, white, n (\%)

Ethnicity, n (\%)

- Not Hispanic or Latino

†Treatment A = 2-min iv. injection HTX-019 130 mg; B = 30-min iv. infusion HTX-019 130 mg.

iv.: Intravenous; SD: Standard deviation.
$\mathrm{AB}^{\dagger}$

$\mathrm{N}=25$

Part B

\begin{tabular}{ll}
$\begin{array}{l}\text { Sequence 2 } \\
\mathrm{BA}^{\dagger}\end{array}$ & Overall \\
$\mathrm{N}=25$ & $\mathrm{~N}=50$ \\
$36(10)$ & $34(9)$ \\
\hline $82(16)$ & $81(16)$ \\
$172(10)$ & $173(11)$ \\
$27(4)$ & $27(4)$
\end{tabular}

$11(44)$

19 (38)

14 (56)

31 (62)

$17(68)$

19 (38)

46 (92)

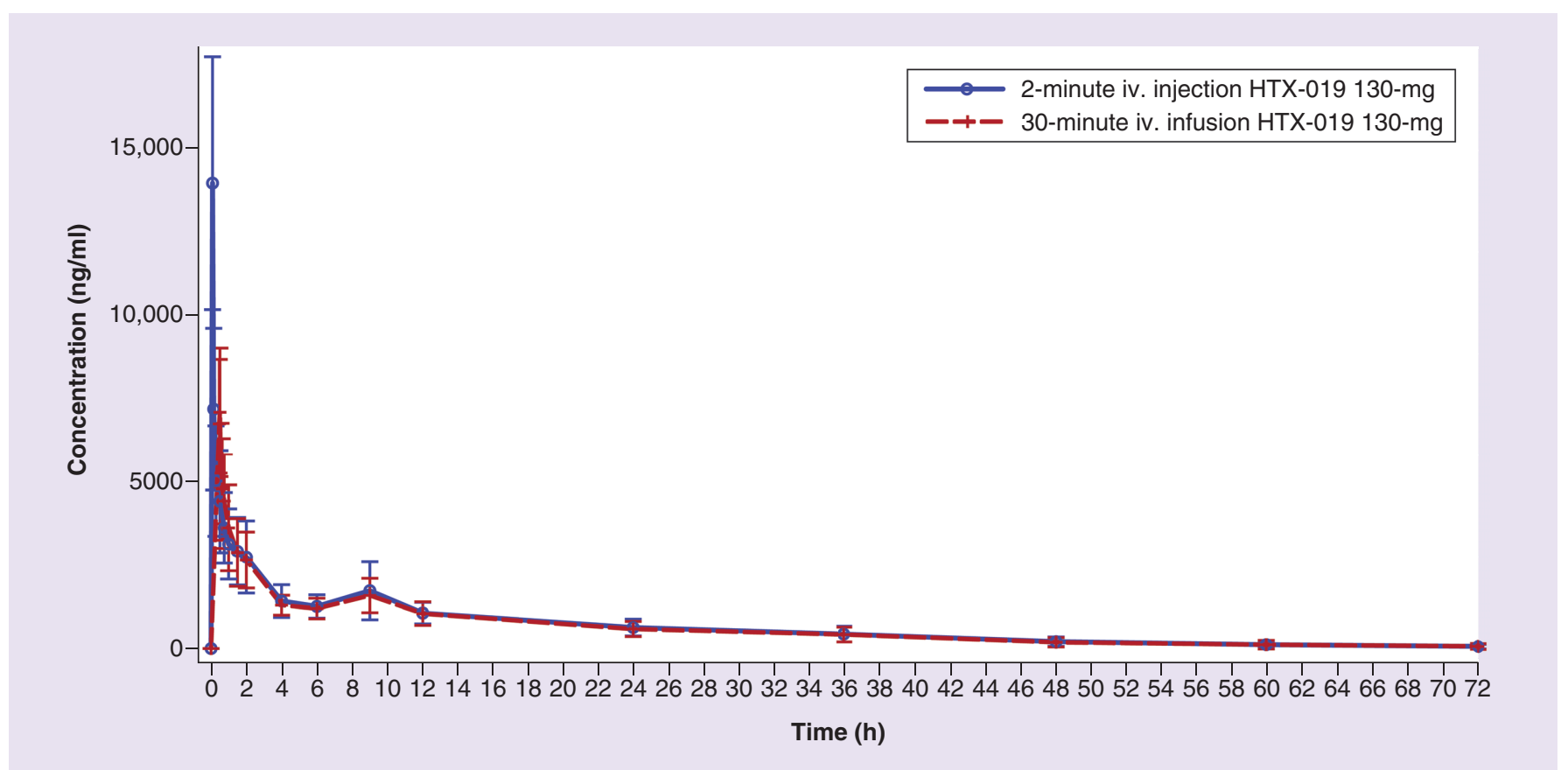

Figure 1. Mean aprepitant plasma concentration-time curve for 2-min injections and 30-min infusions HTX-019 (pharmacokinetics population).

iv.: Intravenous.

Key plasma PK parameters were evaluated between the two methods of administration. Values for AUC 0 -last, $\mathrm{AUC}_{0 \text {-inf }}$ and $\mathrm{t}_{1 / 2}$ were comparable between injections and infusions (Table 2). As expected, $\mathrm{C}_{\max }$ was higher in subjects receiving the injection than in subjects receiving the infusion, and $\mathrm{T}_{\max }$ occurred earlier with the injection versus the infusion (Table 2). More specifically, analysis of bioequivalence for aprepitant indicated that 2-min injections of HTX-019 $130 \mathrm{mg}$ were comparable to 30-min infusions of HTX-019 $130 \mathrm{mg}$ in terms of AUC $\mathrm{A}_{0 \text { last }}$, $\mathrm{AUC}_{0 \text {-inf }}$ and $\mathrm{C}_{12 \mathrm{~h}}$ (Table 3). The geometric LS mean ratios of each of these parameters were close to 1 , and the $90 \%$ CIs around each ratio were within the bioequivalence criteria range of $80-125 \%$ (Table 3). 


\section{Table 2. HTX-019 plasma pharmacokinetic parameters.}

\begin{tabular}{|c|c|c|c|c|c|}
\hline Treatment group & $\mathrm{T}_{\max }(\mathrm{h})$ & $C_{\max }(\mathrm{ng} / \mathrm{ml})$ & $A \cup C_{0 \text {-last }}\left(h^{*} \mathrm{ng} / \mathrm{ml}\right)$ & $A U C_{0 \text {-inf }}\left(h^{*} \mathrm{ng} / \mathrm{ml}\right)$ & $t_{1 / 2}(h)$ \\
\hline 2-min injection & $0.080(0.08-0.20)$ & $13,935(27.0)$ & $45,584(34.0)$ & $47,207(36.1)$ & $13.141(37.6)$ \\
\hline 30-min infusion & $0.500(0.47-0.66)$ & 7201 (27.1) & $42,983(32.3)$ & 44,991 (36.5) & $13.610(41.8)$ \\
\hline
\end{tabular}

Values are presented as mean (\% CV) for all parameters, except for $\mathrm{T}_{\max }$ for which median (range) is presented.

$A \cup C_{0 \text {-inf: }}$ : Area under the plasma concentration-time curve from time 0 extrapolated to infinity; $A \cup C_{0-\text { last }}$ : Area under the plasma concentration-time curve from time 0 to the time of the

last measurable plasma concentration; $C_{\max }$ : Maximum observed plasma concentration; $T_{\max }$ : Time at which $C_{\max }$ occurred; $t_{\frac{1}{2}}$ : Apparent terminal elimination half-life.

\section{Table 3. Summary of bioequivalence analyses for aprepitant (pharmacokinetic population).}

\begin{tabular}{|c|c|c|}
\hline PK parameter & 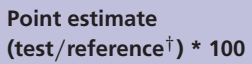 & $90 \% \mathrm{Cl}$ \\
\hline $\mathrm{AUC}_{0 \text {-last }}\left(\mathrm{ng}{ }^{*} \mathrm{~h} / \mathrm{ml}\right)$ & 106.15 & $102.42-110.02$ \\
\hline$A \cup C_{0-\text { inf }}(n g * h / m l)$ & 105.57 & 101.57-109.72 \\
\hline$C_{12 h}(\mathrm{ng} / \mathrm{ml})$ & 102.92 & $98.68-107.35$ \\
\hline
\end{tabular}

$\dagger_{\text {Test }}=2$-min iv. injection HTX-019 $130 \mathrm{mg}$; reference = 30-min iv. infusion HTX-019 $130 \mathrm{mg}$.

$A \cup C_{0 \text {-inf }}$ : Area under the plasma concentration-time curve from time 0 extrapolated to infinity; $\mathrm{AUC}_{0 \text {-last }}$ : Area under the plasma concentration-time curve from time 0 to the time of the

last measurable plasma concentration; $\mathrm{C}_{12 \mathrm{~h}}$ : Plasma concentration at $12 \mathrm{~h}$; PK: Pharmacokinetic.

\begin{tabular}{|c|c|c|c|}
\hline Category/preferred term & $\begin{array}{l}\text { 2-min iv. injection } \\
\text { HTX-019 } 130 \mathrm{mg} \\
(\mathrm{N}=50)\end{array}$ & $\begin{array}{l}\text { 30-min iv. infusion } \\
\text { HTX-019 } 130 \mathrm{mg} \\
(\mathrm{N}=50)\end{array}$ & $\begin{array}{l}\text { Overall }{ }^{\dagger} \\
(\mathrm{N}=50)\end{array}$ \\
\hline Subjects with $\geq 1$ TEAE, $n(\%)$ & $7(14)$ & $9(18)$ & $12(24)$ \\
\hline Subjects with treatment-related TEAE, n (\%) & $6(12)$ & $7(14)$ & $10(20)$ \\
\hline Total number of TEAEs & 8 & 11 & 19 \\
\hline Total number of treatment-related TEAEs & 6 & 9 & 15 \\
\hline Headache & $2(4)$ & $2(4)^{\ddagger}$ & $4(8)$ \\
\hline Fatigue & $1(2)$ & $3(6)$ & $3(6)$ \\
\hline Diarrhea & $2(4)$ & 0 & $2(4)$ \\
\hline Feeling hot h $^{\S}$ & $1(2)$ & $1(2)$ & $2(4)$ \\
\hline Dizziness & 0 & $2(4)$ & $2(4)$ \\
\hline Constipation & 0 & $1(2)$ & $1(2)$ \\
\hline Dyspepsia & $1(2)$ & 0 & $1(2)$ \\
\hline Flatulence & 0 & $1(2)$ & $1(2)$ \\
\hline Sensation of foreign body & $1(2)$ & 0 & $1(2)$ \\
\hline Arthralgia & 0 & $1(2)$ & $1(2)$ \\
\hline \multicolumn{4}{|c|}{$\begin{array}{l}\text { The denominator for percentages was based on the number of subjects in the safety population exposed to each treatment. Subjects with multiple adverse events are only counted } \\
\text { once within each MedDRA level within each preferred term. Events occurring prior to the dose in the second period are classified with the first treatment, and events on or after the } \\
\text { dose in the second period are classified with the second treatment. Events were classified according to MedDRA, Version } 18.1 \text {. } \\
\text { † Due to the crossover nature of the study, if the same adverse event was reported in the first and/or second treatment period by the same subject, the overall column counted the } \\
\text { event only once for that subject. } \\
\ddagger \text { One event occurred during first } 60 \text { min following infusion start. } \\
\text { §occurred during first } 30 \text { min following start of dosing (injection and infusion). } \\
\text { iv.: Intravenous; TEAE: Treatment-emergent adverse event. }\end{array}$} \\
\hline
\end{tabular}

Safety \& tolerability of HTX-019 injection \& infusion

HTX-019 administered via a peripheral line as either an injection or an infusion was well tolerated. The number of TEAEs of any cause and the percentage of subjects experiencing a TEAE were similar in both methods of administration (Table 4). None of the reported TEAEs was fatal, considered serious or led to study drug discontinuation or study withdrawal. All TEAEs were mild in severity and resolved by the end of the study. No TEAEs of dyspnea were reported.

Six treatment-related TEAEs, classified by the investigator, occurred in six of 50 subjects (12\%) in the 2-min injection, and nine treatment-related TEAEs occurred in seven of 50 subjects (14\%) in the 30-min infusion (Table 4). The most common treatment-related TEAE in the 2-min injection group was headache (in two of 50 
subjects; 4\%). The most common treatment-related TEAEs in the subjects receiving the 30-min infusion were fatigue (in three of 50 subjects; $6 \%$ ) and dizziness and headache (in $4 \%$ of subjects each). The only TEAE occurring in the first $30 \mathrm{~min}$ of administration was feeling hot in one subject (2\%) in the 2-min injection group and one subject (2\%) in the 30-min infusion group. Furthermore, one subject in the infusion group experienced a headache in the first $60 \mathrm{~min}$ following the start of dosing.

\section{Discussion}

HTX-019 $130 \mathrm{mg}$ administered as a 2-min injection or a 30-min infusion in this crossover study resulted in comparable PK and safety profiles for aprepitant, and both methods of administration were well tolerated. Evaluation of aprepitant plasma concentrations showed systemic aprepitant exposures were comparable, while $\mathrm{C}_{\max }$ was reliant on the duration of dosing (injection or infusion). Maximum concentrations of aprepitant (2-min injection 13,935 ng/ml; 30-min infusion $7201 \mathrm{ng} / \mathrm{ml}$ ) for both methods occurred briefly, lasting only a few minutes before rapidly decreasing by $\sim 4 \mathrm{~h}$ postdose and remaining quantifiable until $72 \mathrm{~h}$ postdose.

Using PK parameters ( $\mathrm{AUC}_{0 \text {-last }}, \mathrm{AUC}_{0 \text {-inf }}, \mathrm{C}_{12 \mathrm{~h}}$ ), bioequivalence was demonstrated between the 2-min injection and the 30-min infusion of HTX-019 $130 \mathrm{mg}$, as the $90 \%$ CIs for the geometric LS mean ratios were all within the standard bioequivalence range (80-125\%). The higher $\mathrm{C}_{\max }$ of aprepitant following injections compared with infusions was anticipated, so $\mathrm{C}_{\max }$ was excluded from bioequivalence evaluations.

HTX-019 was well tolerated; the overall proportions of subjects experiencing at least one TEAE were comparable between the 2-min injection and the FDA-approved 30-min infusion (14 vs 18\%, respectively). Overall, 12 of 50 subjects had at least one TEAE (19 events), ten (20\%) of whom had 15 TEAEs that were deemed related to the study drug. Because the study was conducted in healthy volunteers, the relationship between TEAEs and HTX019 could be evaluated without any confounding effects from concomitant chemotherapy or other concurrent medications. The most common treatment-related TEAEs were diarrhea and headache (in $4 \%$ of subjects each) following the 2-min injection, whereas fatigue $(6 \%)$, dizziness (4\%) and headache $(4 \%)$ were the most common treatment-related TEAEs following the 30-min injection.

The rate of TEAEs observed with HTX-019 2-min injections versus 30-min infusions in the current study was consistent with the rates seen with HTX-019 30-min infusions in the two bioequivalence studies that resulted in the FDA approval of HTX-019 [10,11]. These studies showed that single-dose HTX-019 $130 \mathrm{mg}$ iv. infused over $30 \mathrm{~min}$ was bioequivalent to single-dose fosaprepitant $150 \mathrm{mg}$ iv. infused over $30 \mathrm{~min}$ (study 104) [10] and 20 min (study 106) [11]. HTX-019 was generally well tolerated, with a consistent safety profile across the two studies; a pooled analysis of both studies showed that the most commonly reported TEAEs at any time were headache (in 3\% of subjects) and fatigue (2\%) after HTX-019 administration, and ISAEs $(10 \%)$ and headache (7\%) after fosaprepitant administration. Overall, the proportion of subjects who reported any TEAEs and the number of TEAEs were lower with HTX-019 $130 \mathrm{mg}$ (30-min infusion) than with fosaprepitant $150 \mathrm{mg}$ (20- or 30-min infusion), as were the proportion of subjects with treatment-related TEAEs and the number of treatment-related TEAEs [10]. In the pooled safety analysis, no HSRs or ISAEs were reported within the first 30 min of HTX-019 infusion [11]. In addition and consistent with the two bioequivalence studies [10,11], HTX-019 treatment was not associated with any severe TEAEs or deaths in the current study.

Commercially available fosaprepitant includes polysorbate 80 , which is associated with numerous adverse reactions, including HSRs $[7,8]$. The prescribing information for fosaprepitant includes a warning and precaution concerning HSRs (anaphylaxis and anaphylactic shock) and was recently updated to include ISAEs as well [6]. Unlike fosaprepitant, HTX-019 is a polysorbate 80- and synthetic surfactant-free aprepitant injectable emulsion. Another NK-1 RA, rolapitant iv., was approved in 2017 for administration in combination with other antiemetics for CINV prevention [14,15]. This formulation contains the synthetic surfactant HS-15. An FDA MedWatch safety alert issued on 16 January 2018, to healthcare providers, warned about HSRs, including anaphylaxis and anaphylactic shock, which may occur during or following administration of rolapitant iv. [16]. Subsequently, on 28 February 2018, the manufacturer announced the suspension of rolapitant iv. distribution [17].

The approved dosage of HTX-019 is 100 or $130 \mathrm{mg}$ infused over $30 \mathrm{~min}$ [9]. However, a significant acute shortage of small-volume parenteral solutions, including those used for HTX-019 dilution, was announced by the 
FDA in November 2017. The FDA referred clinicians to a detailed clinical recommendation from the American Society of Health-System Pharmacists, recommending that clinicians switch administration of products to an iv. push (injection over 5 min or less) whenever possible [12]. Since in Part A of the study, HTX-019 was well tolerated when administered both over $5 \mathrm{~min}$ and as a 2 -min injection, the faster, more convenient 2-min injection was selected for Part B. The current study therefore addressed the American Society of Health-System Pharmacists recommendation by showing that a 2-min injection and a 30-min infusion of HTX-019 $130 \mathrm{mg}$ had comparable PK and safety profiles.

\section{Conclusion}

These findings demonstrate that a short injection of HTX-019 has a tolerable safety profile, and may be used as a potential alternative method of administration in CINV prevention while reducing the need for iv. bags.

\section{Summary points}

\section{Background}

- HTX-019 (CINVANTI ${ }^{\circledR}$ [aprepitant injectable emulsion]) is a neurokinin 1 receptor antagonist (NK-1 RA) free of polysorbate 80 and other synthetic surfactants, and is approved as a 30-min infusion for prevention of acute and delayed chemotherapy-induced nausea and vomiting (CINV).

- In multiple reports, HTX-019 showed bioequivalence to and a more favorable safety profile than the NK-1 RA fosaprepitant.

- A current acute shortage of small-volume parenteral solutions has led to the American Society of Health-System Pharmacists recommendation to administer HTX-019 via intravenous push (injection of 5 min or less).

Objectives \& methodology

- In a two-part study, the primary objective of Part B was to evaluate the pharmacokinetics of plasma aprepitant following a single dose of HTX-019 $130 \mathrm{mg}$ administered intravenously as a 2-min injection or as a 30-min infusion.

- The secondary objective was to assess the safety and tolerability of a single dose of HTX-019 $130 \mathrm{mg}$ administered over the same injection or infusion times.

- Part B was an open-label, randomized (1:1), two-sequence, two-period crossover study in which 50 subjects received a 2-min injection (9 ml/min) and 30-min infusion (296 ml/h) of HTX-019 $130 \mathrm{mg}$.

Pharmacokinetics, efficacy \& safety evaluations

- Blood samples were collected at defined time points predose and postdose; bioequivalence was demonstrated for HTX-019 injection and infusion.

- Safety evaluations included TEAEs, vital signs, clinical laboratory testing and electrocardiograms; both administration methods were well tolerated.

Discussion

- HTX-019 $130 \mathrm{mg}$ administered as a 2-min injection or a 30-min infusion resulted in comparable PK and safety profiles for aprepitant, and both methods of administration were well tolerated.

- These findings address the American Society of Health-System Pharmacists recommendation and confirm the short injection of HTX-019 as a potential alternative method of administration in CINV prevention while reducing the need for iv. bags.

Supplementary data

To view the supplementary data that accompany this paper please visit the journal website at:

https://www.futuremedicine.com/doi/suppl/10.2217/fon-2018-0809

Acknowledgements

This study was funded by Heron Therapeutics, Inc., San Diego, CA, USA.

Financial \& competing interests disclosure

T Ottoboni, M Lauw, MR Keller, M Cravets, K Manhard, N Clendeninn and B Quart report employment by and stock options in Heron Therapeutics, Inc. The authors report no other conflicts of interest in this work. The authors have no other relevant affiliations or financial involvement with any organization or entity with a financial interest in or financial conflict with the subject matter or materials discussed in the manuscript apart from those disclosed.

Writing assistance was utilized in the production of this manuscript. Medical writing support was provided by P Giannopoulos and YE Yarker of SciStrategy Communications, and funded by Heron Therapeutics, Inc. 
Ethical conduct of research

This study was conducted in accordance with the International Conference on Harmonisation Guideline for Good Clinical Practice and the Declaration of Helsinki. The study was approved by the institutional review board for the single study site, Spaulding Clinical Research, LLC, West Bend, WI, USA. Written informed consent was obtained from each subject.

Data sharing statement

The authors certify that this manuscript reports original clinical trial data. Individual participant data that underlie the results reported in this article after deidentification (text, tables, figures, and appendices) are available, including the study protocol. Data requests should be submitted in the form of a research proposal for up 36 months after publication date. Information on submitting a research proposal can be found at: www.herontx.com/grants-and-sponsorships

\section{Open access}

This work is licensed under the Attribution-NonCommercial-NoDerivatives 4.0 Unported License. To view a copy of this license, visit http://creativecommons.org/licenses/by-nc-nd/4.0/

\section{References}

Papers of special note have been highlighted as: $\bullet$ of interest; $\bullet \bullet$ of considerable interest

1. Navari RM. HTX-019: polysorbate 80- and synthetic surfactant-free neurokinin 1 receptor antagonist for chemotherapy-induced nausea and vomiting prophylaxis. Future Oncol. 15(3), 241-255 (2019).

2. NCCN Clinical Practice Guidelines in Oncology: Antiemesis - Version 3.2018. www.nccn.org/professionals/physician_gls/def ault.aspx\#supportive

3. Herrstedt J, Roila F, Warr D et al. 2016 Updated MASCC/ESMO consensus recommendations: prevention of nausea and vomiting following high emetic risk chemotherapy. Support. Care Cancer 25(1), 277-288 (2017).

4. Hesketh PJ, Kris MG, Basch E et al. Antiemetics: American Society of Clinical Oncology clinical practice guideline update. J. Clin. Oncol. 35(28), 3240-3261 (2017).

5. Roila F, Warr D, Hesketh PJ et al. 2016 updated MASCC/ESMO consensus recommendations: prevention of nausea and vomiting following moderately emetogenic chemotherapy. Support. Care Cancer 25(1), 289-294 (2017).

6. Emend (fosaprepitant) for injection, for intravenous use, prescribing information. Merck \& Co, NJ, USA (2018).

7. Coors EA, Seybold H, Merk HF, Mahler V. Polysorbate 80 in medical products and nonimmunologic anaphylactoid reactions. Ann. Allergy Asthma. Immunol. 95(6), 593-599 (2005).

8. Ten Tije AJ, Verweij J, Loos WJ, Sparreboom A. Pharmacological effects of formulation vehicles: implications for cancer chemotherapy. Clin. Pharmacokinet. 42(7), 665-685 (2003).

9. Cinvanti (aprepitant) injectable emulsion, for intravenous use, prescribing information. Heron Therapeutics, CA, USA (2017).

•. Provides HTX-019 prescribing information.

10. Ottoboni T, Keller MR, Cravets M, Clendeninn N, Quart B. Bioequivalence of HTX-019 (aprepitant IV) and fosaprepitant in healthy subjects: a Phase I, open-label, randomized, 2-way crossover evaluation. Drug Des. Devel. Ther. 12, 429-435 (2018).

-. Phase I trial of HTX-019 demonstrating bioequivalence of HTX-019 to fosaprepitant.

11. Ottoboni T, Lauw M, Keller MR et al. Safety of HTX-019 (IV aprepitant) and fosaprepitant in healthy subjects. Future Oncol. 14(27), 2849-2859 (2018).

-. Phase I trial of HTX-019 demonstrating a safer and more tolerable profile of HTX-019 compared with fosaprepitant.

12. SHP and the University of Utah Drug Information Service. Small-volume parenteral solutions shortages: suggestions for management and conservation. www.fda.gov/downloads/Drugs/DrugSafety/DrugShortages/UCM582461.pdf

-• US FDA communication of an acute shortage in small-volume parenteral solutions, which led to the American Society of Health-System Pharmacists recommendation to switch administration to intravenous push.

13. Prakash R. Determination of aprepitant in human plasma by using LC-MS/MS with electrospray ionization. J. Bioequiv. Availab. 5(3), 111-117 (2013).

14. Varubi (rolapitant) tablets, for oral use. Varubi (rolapitant) injectable emulsion, for intravenous use, prescribing information. Tesaro Inc., MA, USA (2018).

15. Wang X, Zhang ZY, Powers D et al. Bioequivalence of intravenous and oral rolapitant: results from a randomized, open-label pivotal study. J. Clin. Pharmacol. 57(12), 1600-1606 (2017).

16. US FDA. Varubi (rolapitant) injectable emulsion: health care provider letter - anaphylaxis and other serious hypersensitivity reactions. (2018). www.fda.gov/Safety/MedWatch/SafetyInformation/SafetyAlertsforHumanMedicalProducts/ucm592592.htm 
- FDA warning of anaphylaxis, anaphylactic shock and other serious hypersensitivity reactions reported in the postmarketing setting, occurring during or soon after the infusion of rolapitant injectable emulsion.

17. Source: Tesaro. Tesaro announces fourth-quarter and full-year 2017 operating results. Press release: http://ir.tesarobio.com/news-releases/news-release-details/tesaro-announces-fourth-quarter-and-full-year-2017-operating

- Announces rolapitant intravenous formulation suspension by manufacturer due to patient hypersensitivity to any ingredient in its formulation. 